\title{
Telemedicine in respiratory sleep medicine: COVID-19 pandemic unmasks the need for a process-oriented, replicable approach for implementation in clinical routine
}

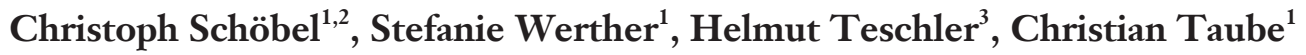 \\ ${ }^{1}$ Department for Pneumology, University Medicine Essen, Ruhrlandklinik - West German Lung Center, Essen, Germany; ${ }^{2}$ Center for Sleep- and \\ Telemedicine, University Medicine Essen, Ruhrlandklinik - West German Lung Center, Essen, Germany; ${ }^{3}$ Institute for Digital Sleep Medicine, \\ Essen, Germany \\ Correspondence to: Christoph Schöbel. Department for Pneumology, Center for Sleep- and Telemedicine, University Medicine Essen, Ruhrlandklinik \\ - West German Lung Center, Tüschener Weg 40, D-45239 Essen, Germany. Email: Christoph.Schoebel@rlk.uk-essen.de.
}

Submitted Jun 24, 2020. Accepted for publication Sep 28, 2020.

doi: 10.21037/jtd-cus-2020-011

View this article at: http://dx.doi.org/10.21037/jtd-cus-2020-011

According to new epidemiological data, sleep disordered breathing $(\mathrm{SDB})$ is considered a widespread disease (1). SDB is considerably underdiagnosed and associated with substantial morbidity and mortality as well as risks for the society (e.g., accidents in traffic and at work). Due to the imbalance between SDB-prevalence and limited care capacities, high numbers of untreated patients suffering from SDB are suspected. If diagnosed, patients with relevant SDB should be treated according to actual guidelines (2). Positive airway pressure (PAP) therapy is regarded as first line therapy with the utmost scientific evidence (3). Regular PAP-treatment is an essential prerequisite for short- and long-term positive effects on subjective and objective outcomes. In order to ensure PAP-adherence, educational, behavioral and troubleshooting interventions have been investigated.

With digitalization of medicine, telemedical approaches got into focus. Randomized controlled trials (RCTs) investigated the impact of remote monitoring of PAP variables to trigger early interventions to assure therapy adherence. Studies demonstrated a significant improvement in PAP-adherence in adults with OSA using telemonitoring compared to usual care. Regarding outcomes, cost effects, benefits for and satisfaction of patients, study results are varying depending on telemedical management as shown in a recent review (3). Recently, the American Academy of Sleep Medicine (AASM) published a telemedicine position paper, a sleep telemedicine implementation guide as well as a video tutorial for introducing telemedicine into practice (4).
However, these publications rather focus on necessary personnel, structural, technical and legal requirements than on structured, process-oriented telemedical intervention descriptions. However, the latter are a prerequisite for the development and evaluation of a replicable telemedical management in respiratory sleep medicine before any implementation in clinical routine.

Currently, COVID-19 pandemic fuels the need for implementation of telemedicine in clinical routine. This is in order to prevent unnecessary traveling and faceto-face consultations of SDB-patients-on one hand to reduce exposure time and lower infection risk for those risk patients, on the other hand to provide clinical capacities for COVID-19 patients. Most recently, Grote et al. published a research letter on the impact of COVID-19 pandemic on sleep apnoea management in Europe by using data from the European Sleep Apnoea Database (ESADA) (5). According to these data, telemedicine based follow ups were only practiced by a minority of centers with even lowering trends during the pandemic. Unexpectedly, this is in extreme contrast to the potential impact of telemedicine in the field of SDB, especially in current times. Grote et al. argued about uncertainty relating to data protections and inadequate practical experiences as limitations for the dissemination of such technology.

However, beside insufficient reimbursement for sleep telemedicine in most countries, the absence of structured and replicable descriptions of telemedical interventions has to be blamed as a main cause for missing practical 
implementation.

Transmitting data remotely without any defined action provoked by these data is just telemonitoring. Pure data can be transformed into beneficial outcomes only with the help of a human touch-defining the term telemedicine: patients and clinicians encounter transmitted data by using electronic communication.

Modern medicine is based on evidence relying on result reproducibility of clinical trials. In contrast, studies dealing with new digital tools like telemedicine often lack clearly defined descriptions of interventions as a prerequisite for methods reproducibility. Thus, only a process-oriented, structured approach can be the basis for replicable and reliable RCTs dealing with telemedical management. This would also help to assess resources for telemedical programs to claim for appropriate reimbursement based on patientcentered outcomes.

In 2014, an international group of experts developed the Template for Intervention Description and Replication (TIDieR) checklist and guide in order to improve the replicability of interventions to be applied on evaluative study designs (6). The checklist comprises and explains 12 items covering topic, rationale, materials, procedures, intervention providers, modes of delivery, necessary infrastructure, frequency and intensity of interventions, adaptations and modifications during the course as well as modalities to assess adherence and the extent of delivered interventions.

Such an adapted checklist could boost methods reproducibility of telemedical management by supporting clinical scientists to structure study interventions. This would also help editors, reviewers, readers and other stakeholders to assess the usefulness of clearly described telemedical interventions-a basic requirement for future implementation and reimbursement of telemedical management strategies in clinical routine.

The article of Grote et al. reveals the existing huge gap between the needs and possibilities of telemedicine and the current practical use in sleep medicine. Therefore we recommend setting up an international task force in order to define a process-oriented, replicable telemedical management of patients with SDB. In particular the restrictions caused by COVID-19 have made clear that our patients can only be treated adequately, if we add telemedical methods wisely to our established tools.

\section{Acknowledgments}

Funding: None.

\section{Footnote}

Provenance and Peer Review: This letter was commissioned by the Guest Editor (Joerg Steier) for the series " 5 th Clinical Update Sleep" published in Fournal of Thoracic Disease. The article was sent for external peer review.

Conflicts of Interest: All authors have completed the ICMJE uniform disclosure form (available at http://dx.doi. org/10.21037/jtd-cus-2020-011). The series " $5^{\text {th }}$ Clinical Update Sleep" was commissioned by the editorial office without any funding or sponsorship. CS reports grants and other from Novartis, grants and other from ResMed, other from Löwenstein Medical, grants from novamed, grants from JAZZ, other from Berlin Chemie, other from BristolMyers Squibb, grants and other from Astra Zeneca, outside the submitted work. The other authors have no other conflicts of interest to declare.

Ethical Statement: The authors are accountable for all aspects of the work in ensuring that questions related to the accuracy or integrity of any part of the work are appropriately investigated and resolved.

Open Access Statement: This is an Open Access article distributed in accordance with the Creative Commons Attribution-NonCommercial-NoDerivs 4.0 International License (CC BY-NC-ND 4.0), which permits the noncommercial replication and distribution of the article with the strict proviso that no changes or edits are made and the original work is properly cited (including links to both the formal publication through the relevant DOI and the license). See: https://creativecommons.org/licenses/by-nc-nd/4.0/.

\section{References}

1. Benjafield AV, Ayas NT, Eastwood PR, et al. Estimation of the global prevalence and burden of obstructive sleep apnoea: a literature-based analysis. Lancet Respir Med 2019;7:687-98.

2. Mayer G, Arzt M, Braumann B, et al. S3-Leitlinie Nicht erholsamer Schlaf / Schlafstörungen, Kapitel Schlaf-bezogene Atmungsstörungen bei Erwachsenen. Somnologie 2017. Sonderheft 2.

3. Patil SP, Ayappa IA, Caples SM, et al. Treatment of Adult Obstructive Sleep Apnea With Positive Airway Pressure: An American Academy of Sleep Medicine Systematic Review, Meta-Analysis, and GRADE Assessment. J Clin 
Sleep Med. 2019;15:301-34.

4. Available online: https://aasm.org/clinical-resources/ telemedicine/ (last access: 05/13/20, 1:53 pm CET).

5. Grote L, McNicholas WT, Hedner J, et al. Sleep apnoea management in Europe during the COVID-19 pandemic: data from the European Sleep Apnoea Database (ESADA).
Eur Respir J 2020;5 5:2001323.

6. Hoffmann TC, Glasziou PP, Boutron I, et al. Better reporting of interventions: template for intervention description and replication (TIDieR) checklist and guide. BMJ 2014;348:g1687.

Cite this article as: Schöbel C, Werther S, Teschler H, Taube C. Telemedicine in respiratory sleep medicine: COVID-19 pandemic unmasks the need for a process-oriented, replicable approach for implementation in clinical routine. J Thorac Dis 2020;12(Suppl 2):S261-S263. doi: 10.21037/jtd-cus-2020-011 